\title{
The Influence of Central Regulation Methods upon Annual Heat Loss in Heating Network
}

\author{
Xiaofang Shan, Peng Wang, Panhong Ren and Hua Zhao \\ School of Municipal \& Environmental Engineering, Harbin Institute of Technology, Harbin, China
}

\begin{abstract}
For directly buried hot water heating network, heat loss per unit length can be calculated by the thermal theory of heating network, then the calculating method of annual heat loss would be deduced. By comparing the heat loss of three different regulation schemes, it is detected that different regulation scheme has different supply and return water temperature, resulting in different heat loss. The heat loss of variable flow regulation of equivalent temperature difference is the largest, while the heat loss of constant flow regulation is the smallest, which has significant guiding to the operation of district heating system. Finally, based on the calculation of the annual heat loss of the heating network in Jiu Tai, Ji Lin Province, it is found that the distribution heat losses take up $2.4 \% \sim 2.7 \%$ of the total supplying heat, which are equivalent to the heat consumptions of the heating area from $30.7 \times 10^{4} \mathrm{~m}^{2}$ to $34.4 \times 10^{4} \mathrm{~m}^{2}$. Therefore reducing the heat losses of large scale heating networks is imminent
\end{abstract}

\section{Introduction}

With the popularization of district heating in industrial and civil buildings, heating industry is becoming a large energy consumer as well as the object of energy saving and emission reduction. Therefore how to decrease heat loss that includes distribution heat loss and hot water loss is one of important parts of energy saving in heating system. The researches of heat loss in developed Europe start quite early, they mainly study the influence factors of heat loss. Frieder Schmitt etc[1].studied the influence of pipe codes, heat insulation materials, methods to pipeline installation, supply and return water temperature, pipe buried depth and so on to heat loss systematically, thus proposing efficient ways to reduce heat loss. In China, the research of heat loss is mainly focused on theory. For example, Wang Zide[2] studied and analyzed thermal calculation of directly buried installation heating pipeline in theory. However, the method of heat loss calculation is relatively rare. Since directly buried heating pipeline has great advantage in water proof, anticorrosion and decreasing heat loss, and directly buried pipes are usually prefabricate by manufacturer, which reduces construction difficulties, thus prefabricated directly buried insulating pipes are widely used. At present, the insulating material of prefabricated pipes is hard polyurethane foam, and the outer protective pipe is high density polyethylene with high performance of thermal insulation and water proof [3]. Therefore, the study of heat loss of widely used directly buried installation heating network has practical sense. This paper systemically introduces the calculation of heat loss and annual heat loss of directly buried heating network, and furtherly analyzes the primary influence factor of heat loss that is supply and return water temperature, which has active guidance to the design and operation of heating system. Then, taking heating network in Jiu Tai, $\mathrm{Ji}$ Lin Province as an example, annual hear loss is calculated as well as the percentage of heat loss in total heating quantity, which provides complete thoughts and methods for calculation of heat losses.

\section{Heat loss calculations}

\subsection{Calculation for Heat Loss per Unit Length}

Because heat loss is affected by many factors, such as warm fluid temperature inside the pipe, thickness of insulating layer, heat conductivity for soil, distance between pipe centres and ground surface, heat flow between pipes and so on, which makes it quite complex to build models and solve them. In engineering application, in order to shorten calculating time and reduce complexity of large scale heating network, there are some rational hypotheses to make calculate easier within a reasonable error range. This paper has the following hypotheses for heat loss calculation [4]:

(1) Soils are isotropic medium, and heat transfer between pipes and soils are homogenized.

(2) Neglecting temperature drop in respective directions of flow, heat transfer could be simplified to be two-dimensional.

(3) Insulating materials are constant-property that does not change with the temperature. 
(4) The heat resistance of pipe wall is always neglected since it is very small. It can be approximatively thought that the temperature of pipe wall is the same as the temperature inside the pipe.

By simplifying boundary conditions and calculation methods, when heating pipes are buried in parallel, heat losses of supply pipe can be calculated with the following formula:

$$
q_{g}=\frac{\left(t_{g}-t_{w}\right)\left(R_{b}+R_{w}+R_{t}\right)-\left(t_{h}-t_{w}\right) R_{c}}{\left(R_{b}+R_{w}+R_{t}\right)^{2}-R_{c}^{2}}
$$

Heat losses of return pipe can be calculated with the following formula:

$$
q_{h}=\frac{\left(t_{h}-t_{w}\right)\left(R_{b}+R_{w}+R_{t}\right)-\left(t_{g}-t_{w}\right) R_{c}}{\left(R_{b}+R_{w}+R_{t}\right)^{2}-R_{c}^{2}}
$$

With the following definitions:

$t_{g}=$ supply water temperature $\left[{ }^{\circ} \mathrm{C}\right]$

$t_{h}=$ return water temperature $\left[{ }^{\circ} \mathrm{C}\right]$

$t_{w}=$ ambient air temperature $\left[{ }^{\circ} \mathrm{C}\right]$

$R_{b}=$ insulation resistance $\left[\mathrm{m}^{2} \mathrm{~K} / \mathrm{W}\right]$

$R_{w}=$ outer pipe resistance $\left[\mathrm{m}^{2} \mathrm{~K} / \mathrm{W}\right]$

$R_{t}=$ ground resistance $\left[\mathrm{m}^{2} \mathrm{~K} / \mathrm{W}\right]$

$R_{c}=$ coinciding resistance $\left[\mathrm{m}^{2} \mathrm{~K} / \mathrm{W}\right]$

Firstly, according to the heat conduction formula of the cylinder [5], insulation resistance can be calculated with the following formula:

$$
R_{b}=\frac{1}{2 \pi \lambda_{b}} \ln \frac{D_{b}}{D_{o}}
$$

With the following definition:

$\lambda_{b}=$ heat conductivity for insulation $[\mathrm{W} / \mathrm{mK}]$

$D_{b}=$ outer insulation diameter $[\mathrm{m}]$

$D_{o}=$ outer pipe diameter $[\mathrm{m}]$

Outer pipe resistance can be calculated with the following formula [5]:

$$
R_{w}=\frac{1}{2 \pi \lambda_{w}} \ln \frac{D_{w}}{D_{b}}
$$

With the following definition:

$\lambda_{w}=$ heat conductivity for outer pipe $[\mathrm{W} / \mathrm{mK}]$

$D_{w}=$ outer pipe diameter with protective pipe [m]

The ground resistance is generally calculated by virtual heat source method. Virtual heat source method assumes there a line heat source at some point in the middle of the pipe, and its heat productivity $q_{l}$ is equal to the heat productivity of pipe surface. At the same time, the method also assumes that there is line heat congruence, a negative line heat source, whose heat productivity is $-q_{l}$ at its symmetric point regarded the ground surface as the symmetry axis. By superimposing the thermal fields of two heat sources, then we can use the final thermal field to simulate thermal field of directly buried pipes to detect the ground resistance. When the buried depth of pipes is deeper, the ground resistance can be approximately calculated with the following formula [5]:

$$
R_{t}=\frac{1}{2 \pi \lambda_{t}} \ln \frac{4 H}{D_{w}}
$$

With the following definition:

$\lambda_{t}=$ heat conductivity for ground $[\mathrm{W} / \mathrm{mK}]$

$\mathrm{H}=$ converted buried depth of pipes [m]

Because convective heat transfer should be considered while calculating heat loss of pipes, converted buried depth of pipes can be calculated with the following formula:

$$
H=h+\frac{\lambda_{t}}{a_{k}}
$$

With the following definition:

$h=$ the distance from the ground surface to the central of pipes [m]

$a_{k}=$ heat transfer coefficient of ground, $12 \sim 15 \mathrm{~W} / \mathrm{mk}$,

When the pipes of heating network are installed in parallel, the heat transfer between two pipes should be considered. According to the method proposes by Szubin, the Soviet Union Scholar, the influence between two pipes could be simplified as a coinciding resistance $R_{c}$ [6]. So the coinciding resistance can be calculated with the following formula:

$$
R_{c}=\frac{1}{2 \pi \lambda_{t}} \sqrt{\left(\frac{2 H}{b}\right)^{2}+1}
$$

With the following definition:

$b=$ distance between centers of two pipes [m]

\subsection{Annual Heat Losses Calculation}

For traditional heating system, supply and return water temperature as requested regulations varies with the outdoor temperature, and heat loss varied as well during heating period. So annual heat losses are affected by outdoor temperature and corresponding heating hours, and annual heat losses can be calculated with the following formula:

$$
Q_{l}=\sum_{j=1}^{k} \int_{120}^{N_{p}}\left(q_{g}+q_{h}\right) l_{j} d n
$$

With the following definition:

$Q_{l}=$ annual heat losses [J]

$l_{j}=$ the length of number $\mathrm{j}$ pipe $[\mathrm{m}]$

$\mathrm{k}=$ the total number of calculated pipes

$N_{p}=$ the total heating hours $[\mathrm{h}]$

While calculating annual heat losses, corresponding continuous heating hours $n$ of different outdoor temperature should be defined, and the parameter can be calculated by non-dimensional formula. When design outdoor temperature for heating $t_{w}{ }^{\prime}$, outdoor mean temperature during heating period $t_{p j}$, and heating days $N^{\prime}$ 
are known, based on the non-dimensional formula corresponding heating hours of some outdoor temperature can be calculated with the following formula:

$$
n=\left\{\begin{array}{lc}
120 & t_{w} \leq t_{w}^{\prime} \\
{\left[\left(\frac{1-\left(t_{n}-t_{w}\right) /\left(t_{n}-t_{w}^{\prime}\right)}{\beta_{0}}\right)^{1 / b} \times N^{\prime}+5\right] \times 24 t_{w}^{\prime} \leq t_{w} \leq 5}
\end{array}\right.
$$

In the formula, $\mu=\frac{N^{\prime}-5}{N^{\prime}}, \quad b=\frac{5-\mu t_{p j}}{\mu t_{p j}-t_{w}^{\prime}} \quad$ and $\beta_{0}=\frac{5-t_{w}^{\prime}}{t_{n}-t_{w}^{\prime}}$ are non-dimensional parameters.

\section{Analysises of influence factors of heat loss}

The influence factors of heat loss include buried depth of pipes, supply and return temperature, pipe diameter and so on. For a real heating system, some parameters like buried depth of pipes and pipe diameter, are fixed. So this text analyses the main factor, supply and return temperature. Since supply and return temperature varies with different regulation ways, heat losses of three different regulation ways, constant flow regulation, centralized regulation with flow varied by steps, variable flow regulation of equivalent temperature difference, are discussed, which in fact analyses the effect of supply and return temperature on heat losses.

It is assumed that the heating pipes are prefabricated insulating pipes, steel pipes are $\Phi 630 \times 8$, outer protective pipes are $\Phi 760 \times 11$, insulating materials are polyurethane foam, thickness of insulating layer of supply and return pipes is $\delta=54 \mathrm{~mm}$, heat conductivity for insulation is $\lambda_{b}=0.033 \mathrm{~W} / \mathrm{mK}$, outer protective pipes are high density polyethylene, heat conductivity for outer protective pipes is $\lambda_{w}=0.26 \mathrm{~W} / \mathrm{mK}$, pipes are installed in parallel, the distance between two pipes is $b=0.2 \mathrm{~m}$, mean buried depth from the top of pies to the ground surface is $h=1.3 \mathrm{~m}$, and that design supply and return water temperature of heating network is $\tau_{g}=120^{\circ} \mathrm{C}, \tau_{h}=60^{\circ} \mathrm{C}$ respectively.

During heating period, three different regulation ways are applied, and they are constant flow regulation, centralized regulation with flow varied by steps, and variable flow regulation of equivalent temperature difference. When variable flow regulation of equivalent temperature difference is adopted, temperature difference between supply and return would main at the biggest design temperature difference, and its corresponding supply water temperature is higher than other two regulation ways. Because of higher supply water temperature, the heat losses of supply pipes are bigger than return pipes, leading to bigger heat losses under variable flow regulation of equivalent temperature difference. While constant flow regulation is adopted, the flow of heating system mains constant, supply and return varies with outdoor temperature. For its supply water temperature is lower than supply temperature under variable flow regulation of equivalent temperature difference, its corresponding heat losses are smaller as well. The reason why heat losses of centralized regulation with flow varied by steps is bigger than heat losses of constant flow regulation is that when the flow is decreased, temperature difference between supply and return pipes will increase with supply water temperature increasing. Through the calculation, heat losses of three regulation ways are shown as the following Figure 1.

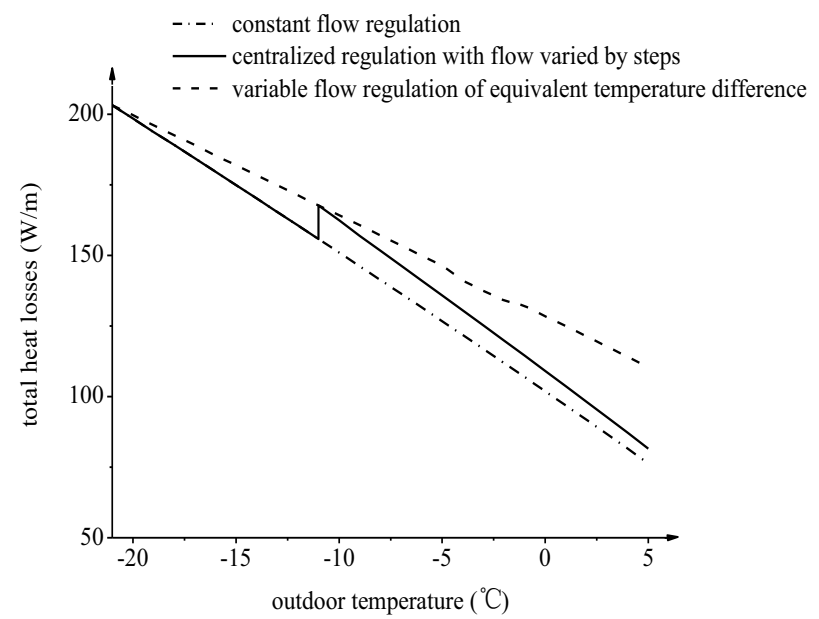

Figure 1. Heat Losses per Unit Length under Different Regulation Ways

As shown in the figure, different regulation ways have different heat losses, and heat losses of constant flow regulation are the smallest; when relative flow coefficient is 1 , heat losses of centralized regulation with flow varied by steps are the same as heat losses of constant flow regulation, but when the relative flow coefficient is 0.75 , in order to main indoor temperature, supply water temperature has to be increased, so in this step heat losses obviously are bigger than heat losses of constant flow regulation; compared to other two regulation ways, heat losses of variable flow regulation of equivalent temperature difference are the biggest.

\section{Annual heat losses of heating network in Jiu Tai}

Long term planning heating area of Jiu Tai heating network is $1250 \times 10^{4} \mathrm{~m}^{2}$, heat load is $676.25 \mathrm{M}$, and design supply and return water temperature is $120 / 60^{\circ} \mathrm{C}$. Heating pipes are prefabricated and directly installed with hard polyurethane foam as insulation layer and high density polyethylene as outer protective pipes, and the buried depth from the top pf pipes to the ground surface is $1.3 \mathrm{~m}$. In Jiu Tai, the design outdoor tempreature for heating is $-21^{\circ} \mathrm{C}$, the number of heating days is 169 , and mean outdoor temperature is $-7.6{ }^{\circ} \mathrm{C}$ during heating peroiod.

\subsection{Annual Heating Consumption of Users}

According to the heating areas and design heat load, space-heating load index per unit floor is $51 \mathrm{~W} / \mathrm{m}^{2}$ 
without regarding heat losses of primary network. Based on heating load duration graph of Jiu Tai, heating consumption is $Q_{y}=\sum Q_{h}=6176735.60 \mathrm{GJ}$.

\subsection{Annual Heat Losses for Primary Network under Different Regulation Methods}

For heating system of Jiu Tai, secondary network is applied with constant flow regulation, and primary network is applied with constant flow regulation, centralized regulation with flow varied by steps(relative flow coefficient of second step is 0.75 ), and variable flow regulation of equivalent temperature difference respectively. The results for three different regulation ways are shown in Figure 2..

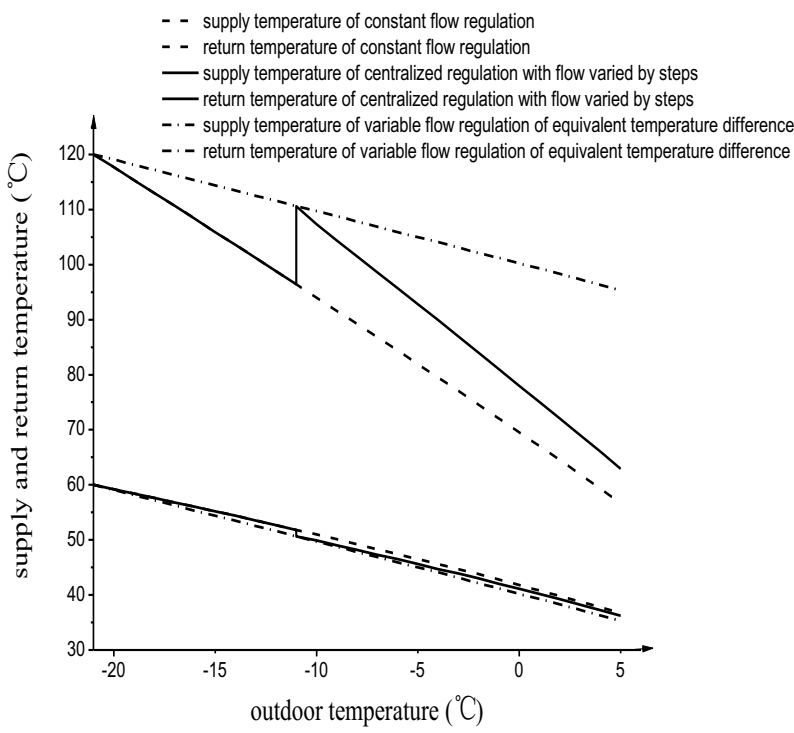

Figure 2 Supply and Return Temperature under Different Regulation Ways

According to Formula 8, annual heat losses under three different regulation ways could be got: annual heat losses for constant flow regulation are $Q_{l}=159906.67 \mathrm{GJ}$; annual heat losses for centralized regulation with flow varied by steps are $Q_{l}=165569.92 \mathrm{GJ}$; annual heat losses for variable flow regulation of equivalent temperature difference are $Q_{l}=178919.67 \mathrm{GJ}$.

\subsection{Added Heating Area of Annual Heat Losses}

In order to calculate added heating area of annual heat losses, according to the definition we should firstly calculate annual heating quantity per square meter $(q)$, and then annual heat losses divided by $q$ equals added heating area because of heat losses. While heating supply quantity includes annual heat consumption for users, heat losses for pipes and heat losses because of lost hot water (assuming that water loss ratio is $2 \%$ of system flow). Therefore, the sum of annual heat consumption for users, annual heat losses and heat losses because of lost hot water equals to total heating supply quantity. Heat transfer coefficient is the ratio of annual consumption for users and total heating supply quantity. The results are shown in Table 1.
Table 1 Added Heating Area of Heat Losses

\begin{tabular}{|c|c|c|c|}
\hline $\begin{array}{c}\text { Regulation } \\
\text { Ways }\end{array}$ & $\begin{array}{c}\text { Constant } \\
\text { Flow } \\
\text { Regulation }\end{array}$ & $\begin{array}{c}\text { Centralized } \\
\text { Regulation } \\
\text { With Flow } \\
\text { Varied By } \\
\text { Steps }\end{array}$ & $\begin{array}{c}\text { Variable Flow } \\
\text { Regulation Of } \\
\text { Equivalent } \\
\text { Temperature } \\
\text { Difference }\end{array}$ \\
\hline $\begin{array}{c}\text { Annual Heat } \\
\text { Consumption } \\
\text { for Users } \\
Q_{\nu}(\mathrm{GJ})\end{array}$ & 6176735.60 & 6176735.60 & 6176735.60 \\
\hline $\begin{array}{c}\text { Annual Heat } \\
\text { Losses } \\
Q_{l}(\mathrm{GJ})\end{array}$ & 159906.67 & 165569.92 & 178919.67 \\
\hline $\begin{array}{c}\text { Total Heating } \\
\text { Supply } \\
\text { Quantity } \\
Q(\mathrm{GJ})\end{array}$ & 6517672.99 & 6523336.18 & 6536.685 .93 \\
\hline $\begin{array}{c}\text { Percentage of } \\
\text { Heat Losses } \\
(\%)\end{array}$ & 2.4 & 2.5 & 2.7 \\
\hline $\begin{array}{c}\text { Added } \\
\text { Heating Area } \\
\left.\text { (m }{ }^{2}\right)\end{array}$ & $30.7 \times 10^{4}$ & $31.8 \times 10^{4}$ & $34.4 \times 10^{4}$ \\
\hline $\begin{array}{c}\text { Heat Transfer } \\
\text { Coefficient } \\
(\%)\end{array}$ & 94.8 & 94.7 & 94.5 \\
\hline
\end{tabular}

From the table, we can find that the percentage of heat losses under three different regulation ways varies from $2.4 \%$ to $2.7 \%$. The added heating area varies from $30.7 \times 10^{4} \mathrm{~m}^{2}$ to $34.4 \times 10^{4} \mathrm{~m}^{2}$. The added heating area under variable flow regulation of equivalent temperature difference is the largest, centralized regulation with flow varied by steps follows, and constant flow regulation is the smallest, which is in consistence with prior analysis.

\section{Conclusion}

From the above analysis, we can know that for the directly buried hot water heating network (prefabricated pipes):

(1) Different regulation ways have different heat loss per unit length. Heat loss of variable flow regulation of equivalent temperature is the biggest, centralized regulation with flow varied by steps follows, and constant flow regulation is the smallest.

(2) According to the calculation of annual heat losses of heating network in Jiu Tai, different regulation ways have different annual heat losses. During heating period, when applied with variable flow regulation of equivalent difference, supply water temperature is the highest with the biggest heat losses. While supply water temperature of constant flow regulation is the lowest with the smallest heat losses, and heat losses of centralized regulation with flow varied by steps are in the middle.

(3) Through the calculation of heating network in Jiu Tai, annual heat losses of primary network take up $2.4 \% \sim 2.7 \%$ of total heating supply quantity. The added heating area under different regulation ways varies from $30.7 \times 10^{4} \mathrm{~m}^{2}$ to $34.4 \times 10^{4} \mathrm{~m}^{2}$. While the scale of heating 
system is bigger, this part of heat losses is becoming bigger as well.

This paper discusses the proportions of heat loss of primary network in total heating supply quantity based on heating network in Jiu Tai. Because the difference of installation ways, heating system scale, routing, and distributions of heat loads, operation temperature and so on, the proportions of heat losses in heating supply quantity are different as well. Heat losses in heating system should analyse case by case. This paper provides calculation methods and research ideas for heat losses of prefabricated and directly buried heating pipes, and proposes some reference for study of heat losses of other types of heating network at the same time.

\section{Acknowledgements}

The authors gratefully acknowledge supports by the National Science \& Technology Pillar Program in the Twelfth Five-year Plan Period (No. 2011BAJ05B04).

\section{References}

1. F. Schmitt, H.W. Hoffmann, T. Gohler. Strategies to Manage Heat Losses. IEA. V II (2005)

2. Zide W. Calculation and Design of Directly Buried Heating Network. G\&T. J. 22, 457 (2002)

3. C.G. Potts, L.M. Draaijer.Developments in Rigid Polyurethane Foams for the Insulation of District Heating Pipelines. J. Cell. Plas. J. 21, 51 (1985)

4. Ping H, Guang S. District Heating Engineering. (Architecture\&Building, China, 2009)

5. Dexing S. Advanced Heat Transfer. (Architecture\&Building, China, 2005)
6. A.A
Lonin.
District
Heating.

(Architecture\&Building, China, 1986) 